\title{
Universal Health Coverage and Primary Health Care: Their Place in People's Health
}

\author{
Christine Walker ${ }^{1}$ and Chris Peterson ${ }^{2}$ \\ ${ }^{1}$ Chronic Illness Alliance \\ ${ }^{2}$ La Trobe University
}

June 11, 2020

\begin{abstract}
Sturmberg and Martin in 2020 argue that Universal Health Care (UHC) is mainly about financing and Primary Health Care (PHC) is about the right care at the right time to ensure health. They maintain the World Health Organisation (WHO) has recently sent the wrong message about the "pillars" of PHC in their relationship to UHC. An understanding of political economy is required in order to come to terms with the bases of PHC and the fundamentals of UHC, that dealing with inequities is not only an economic issue but fundamentally a political issue. Neoliberal decision making can enhance inequities in society. Two chronic health conditions, diabetes and multiple sclerosis are examples of conditions that lead to costly and debilitating consequences for patients but also lead to substantial economic costs in terms of lost workforce participation and lost productivity. These cases demonstrate the socio-political issues involved in the management of care for a number of illnesses. The upsurge of COVID-19 has placed an enormous strain on health and broader social and economic resources and challenged the pretext of UHC as health for all: substantial differences in equity and political commitment have emerged. Sturmberg and Martin argue that the joining of UHC and PHC needs leadership which involves local communities and resourcing. PHC is a changing system based on power relationships involving funders and the health community. In Australia as in several countries out of pocket costs have grown rapidly and have affected access for some groups to PHC and have challenged the pretext of equity in UHC. In the context of PHC and UHC we support the position that health for all goes beyond healthcare for all, to embrace healthy lives promoting wellbeing.
\end{abstract}

\section{Keywords}

Experience; Healthcare; Health policy; Public health

\section{Background}

Sturmberg and Martin ${ }^{1} \mathrm{p}^{1}$ report that UHC' means that all people and communities can use the promotive, preventative, curative, rehabilitative and palliative health services they need, of suffiient quality to be effective' and ensure using these services without financial hardship. UHC is mainly about financing whereas $\mathrm{PHC}$ is 'primarily concerned with providing the right care at the right time to achieve best possible health outcomes for individuals and communities.' 1 p 1

The current global coronavirus crisis has thrown into relief the role of policy and funding in the distribution of healthcare within nations. Countries are now needing to find resilience in healthcare funding in the face of COVID-19. ${ }^{2}$ Access to healthcare varies according to national political economy and political ideology governing and enacting how and under what circumstances a person is eligible for healthcare. The vast interplay between political ideologies, health policy and economic policies have impacts on the health and wellbeing of individuals' lives beyond access to healthcare. In other words, access to healthcare is only one part of access to health. 
The World Health Organisation (WHO) called on researchers in health to suggest ways of strengthening 'the three 'pillars' of primary health care (1) enabling primary care and public health to integrate health services, (2) empowering people and communities to create healthy living conditions, and (3) integrating multisectoral policy decisions to ensure UHC that achieves the goal of "health for all", 1 p1. Sturmberg and Martin argue that "pillars" sends the wrong message for researchers and policy makers. However, calling on the health research community to make such suggestions to achieve 'health for all' neglects that they are subject to the political economy of the nation most often through funding, in which this is being undertaken.

In this article we argue that to ensure that universal health coverage (UHC) addresses inequalities in access to healthcare and strengthens primary health care it is important to analyse how ideologies and policies actively influence health inequities and additionally impact on the scope and efficiency of health services to deliver optimum healthcare. Where neoliberal ideologies hold sway, governments may reduce their funding, hold views about citizens' abilities to pay and erode the 'universal' in UHC.

\section{Political Economy Context}

The WHO ${ }^{3}$ defines UHC as all people and communities can use the promotive, preventive, curative, rehabilitative and palliative health services they need, of sufficient quality to be effective, while also ensuring that the use of these services does not expose the user to financial hardship' . However, adopting UHC to provide healthcare to a population is inherently a political process. ${ }^{4}$ It is also subject to changing political landscapes and the views of health financing. Sparkes et al ${ }^{4}$ argue that the amount of money involved in any healthcare makes it subject to external influences.

Reich ${ }^{5,6}$ suggests a political economy analysis focusing on power and resources, how they are distributed and contested in different country and sector contexts, and the resulting implications for achieving both UHC and health. Analysis of political economy issues requires explorations of the roles of government policies, social movements and commercial interests. It can reveal that inequalities exist within UHC itself such as unequal funding of public health and prevention activities, primary and tertiary care. These exist because of differing powers within a society. It also means that within a healthcare system illnesses will receive differing funding.

Sparkes et al ${ }^{4}$ argue that in the pursuit of universal health coverage analysis of political issues is required. A political economy analysis can aid more effective approaches for managing political issues that arise. Reich

${ }^{5}$ maintains that many policy makers in the health sphere do not know how to undertake political economy analysis despite seeing the need for it. 'The World Health Organization (WHO) can promote evidence-based political economy analysis to assist health policy-makers in managing change more effectively, for instance to move towards universal health coverage (UHC) or to advance other health-related SDGs (Sustainable Development Goals). ${ }^{5}$ p514. Understanding political economy has important implications.

Why is this important to people's health? The decisions made by policy makers across all sectors of government have importance for people, both well and ill and impact their decision-making. It allows for questions of 'in whose interests' are some policies implemented. This in turn has implications for the functioning and levels of satisfaction of patients in PHC and eventual outcomes for UHC.

Bambra Fox and Samuel argued in 2005 there was little mainstream debate on how politics, ideology and power affect the health of people, with some rare exceptions. ${ }^{7}$ Before that the WHO had said these issues had been resolved but that claim is contentious. In 2006, Boxall and Short ${ }^{8}$ argued that some researchers suggest that neo-liberal economies use welfare and labour market policies leading to greater inequality and diminished health outcomes. However, while Australia adopted neoliberal policies its public health remained the best in the world. This claim ignored that health outcomes comparisons internationally are relative. Since 2006 however, economic and social inequities are growing in Australia. ${ }^{9}$ Increasing inequalities pervade the health system so that inequalities exist across within populations and among health conditions.

People experience health, illness and healthcare within a political economy. However, it is usually only when they become ill (or face a pandemic) that the impacts of that political economy become evident. These 
impacts are broad: access to healthcare, to welfare, transport, employment and retaining social integration will be made harder or easier based on the political economy in which they live.

The following are two examples of conditions demonstrating the impact of Australian political economy on the health and well-being of individuals. They demonstrate that policies related to employment, welfare and income all play a role in well-being of those who become ill. At the same time those policies control individuals' access to employment, welfare and income, which in turn can have its own impact on the nation's economy and costs to the health system.

Diabetes: costs to individuals, families and the economy

In 2014 Schofield et al ${ }^{10}$ examined the likelihood of Australian people with diabetes being in work and poverty rates amongst those with diabetes who were unemployed. They found that those with diabetes were more likely not to have employment and those who were unemployed were most likely to live under the poverty line. They concluded that having diabetes, more than any other condition was likely to lead to unemployment and poverty in Australia and that this status exacerbated their abilities to care for their health.

There has been no improvement since then. Healthcare costs of diabetes increased substantially from $2001-$ 2 to $2008-9$ (\$AUD 811 mill to \$AUD 1.51 bill). Indirect costs for the $45-64$ age group were substantially higher. For example, those who left their job due to diabetes had just one third the income of those without the condition.. By 2030 the differences will be substantial. ${ }^{11}$.

Schofield et al ${ }^{11}$ maintain while substantial diabetes direct costs are large, 'the full range of indirect costs (i.e., lost earnings, lost productivity, lost superannuation, lost taxation revenue, carer costs, extra welfare payments, cost of aids and home/work modifications, travel costs) are recognised as being even greater.' These include lost productivity, and reduced capacity to gain and maintain employment as a result of related physical disability.

This impacts on the Australian health system and the broader economy. By 2018, death rates for those with diabetes were nearly double than for the general population in Australia, and for those under 45 years of age with Type 2 diabetes nearly 6 times the prevalence in the general population. ${ }^{12}$

Schofield et al ${ }^{11}$ analysed the costs of diabetes in Australia over time. They projected between 18,100 (2015) and 21,400 (2030) people would be out of the workforce, leading to lost income from \$AUD 467 mill (2015) to almost double that in 2030. In addition, for the government there was a loss of taxation revenue annually from \$AUD 102 mill in 2015 to more than a 50 per cent increase in 2030. It was estimated that a loss in GDP of \$AUD 2.1 bill (2015) would increase to \$AUD 2.9 bill (2030) due to diabetes.

Multiple Sclerosis (MS): costs to individuals, families and the economy

In 2017 there were 25,607 people with MS in Australia; that is 103.7 per 100,000. Total cost of MS was \$AUD 1.75 bill and annual cost per person was \$AUD 68,382 per annum. ${ }^{13}$ MS affects people of working age and can lead to unemployment or underemployment. Twenty two percent of the direct per person cost $(\$ 8,437)$ were borne 'out of pocket' by the people with MS themselves, while government and community jointly incurred $78 \%$ of the direct per person costs $(\$ 21,911)$. The second largest component was the indirect costs from lost wages $(32 \%, \$ 21,858)$. Loss of wages has declined from $50 \%$ of direct costs to $32 \%$ in 2017 , largely due to new generation of disease modifying therapies, which has allowed more people to remain in work. ${ }^{13}$

Chen et al ${ }^{14}$ report on MS days lost that there is a mean total absenteeism of 0.6 days per 4 weeks or 7.8 days per person annually. Symptom severity in people with MS most strongly explains workforce participation and productivity. ${ }^{15}$ They assessed prevalence and impact of 30 comorbidities on participation and productivity in work, and the economic burden and productivity costs of comorbidities. Depression (45\%) followed by anxiety $(42 \%)$, allergies (38\%), migraine (30\%) and high blood pressure $(25 \%)$ were the five most prevalent 
comorbidities. Those reporting limitations to activities had osteoarthritis, followed by depression, anxiety, and allergies.

Productivity loss in the past 4 weeks for those with comorbidities was 2.5 days, approximately 32.5 days per annum (highest for those with osteoporosis, inflammatory bowel disease, osteoarthritis and psoriasis), and 1.3 days, approximately 16.9 days per annum, without comorbidities. In addition, total population costs were greatest per year for those with depression with a cost of \$AUD 33 mill; allergies at \$AUD 33 mill; followed by anxiety, migraines and osteoarthritis. Higher numbers of comorbidities were associated with lost productivity: having one comorbidity compared to none led to $19.8 \%$ productivity loss.

These examples demonstrate that having chronic conditions has health impacts far beyond the health system itself. As well it increases inequalities between those with chronic conditions and those without since the health system takes no account of the value of social health.

\section{Discussion}

In 2020 there has been an enormous impact on social and health systems from COVID-19. The effect is worldwide with social and health ramifications into the future. What is emerging is a new inequity and the focus is on new political processes that deal with UHC under these extreme conditions. ${ }^{16}$

Estimates of the impacts on employment in Australia and hence incomes suggest that at least 3.6 million people will be out of work, with those from hospitality, retail and entertainment industries most hard hit. These are the low paid workers on casual employment with few savings behind them to support them through the pandemic. This includes close to 94,000 casual academics. Casual workers are not eligible for government benefits. $17-19$

Older people especially with chronic conditions are at greater risk if contracting coronavirus. Pre-existing conditions can also create greater risks of severe virus outcomes. ${ }^{20}$. In some countries migrating workers and their poor living conditions have created a greater danger of infection. ${ }^{21}$ Government measures to curb the spread of the virus are leaving many of these same people exposed to greater risks to their physical and mental health. These risks stem from increased exposure to the virus and from increased economic and social hardship during the lockdown. ${ }^{22}$

Inequitable opportunities as the result of economic downturn, after major recessions in the US long term unemployment have been shown to have far reaching effects for future productivity as well as employability. This is especially so for younger people who in slumps are "scarred" 23 having lower wages and fewer employment opportunities in their early careers. In Australia the impact on younger people can be seen from the withdrawals from superannuation (pension schemes). Over 450,00 withdrawals have been made by people $<30$ who have amassed the least savings. ${ }^{24}$ Physical capital has not been destroyed, but the risk of human capital damage is large, through the scarring of significant numbers of unemployed for long periods of time. ${ }^{25}$

The coronavirus pandemic demonstrates the inadequacy of current health systems, particularly with regard to preventive care where Australia spends relatively less. ${ }^{26}$ Restoring health affected by COVID-19 is a longterm prospect which will entail dealing with greater inequities. Delays in education and further studies will affect many and will lead to longer term inequality. However, COVID-19 offers an opportunity to conduct far-reaching reform. Webster ${ }^{27}$ points out in the UK The Independent Scientific Group for Emergencies (SAGE) identified that centralised control was an impediment and undermined local integration of health and social systems, where primary care is the backbone of the system..

Similarly, Sturmberg and Martin ${ }^{1}$ argue that the integration of UHC and PHC requires political leadership which involves local communities and resourcing, this ignores the influences of lobby groups in the health sector on policies and government spending in health, often towards greater medical intervention. As was the case with the UK Government the ideological positions of political leaders may preclude communities participating. 27 
Australian PHC is an ever-evolving system driven by changes in power relations, most notably between funders and health professionals, health professional bodies, lobbyists and within the professions. ${ }^{28,}{ }^{29}$ Whether it can be deemed a system, which suggests some stability is questionable. ${ }^{30}$ The term "navigating the health system" is in common parlance for good reason. Interestingly, in a call for a national minimum data set in primary care, the Deeble Institute ${ }^{31}$ points out that there is little understanding of how and why patients access Australian PHC.

Sturmberg and Martin ${ }^{1}$ call for PHC and UHC to become a "system as a whole framework" where UHC operates as financing PHC then improving parts of the system will lead to improving the whole system. However, until PHC is reformed to operate locally, integrated with local welfare, housing and other services, it can be argued that uniting two damaged systems will lead to further damage and inadequacy for people's health and wellbeing. UHC is rarely universal; this is demonstrated in Australia by the growth of out-ofpocket costs (OOPs) which are currently estimated as $20 \%$ of health costs. ${ }^{32,} 33$ OOPs are comprised of co-payments on prescription medicines, gap fees for GP, specialists, allied health care, plus costs associated with tertiary care. The support of the private health insurance (PHI) industry via tax credits for those able to afford PHI has further undermined UHC in Australia. Another aspect of its lack of universality is the funding of the system, with $39 \%$ of funding in Australia going to tertiary care and $1.34 \%$ in $2013-14$ to preventive health services. ${ }^{34,35}$

\section{Conclusion}

While UHC and its leadership should produce greater equality and PHC should include social housing as Sturmberg and Martin argue, this is patently not the case. Public policies about health currently actively exclude economic policies that impact on people's participation in health-maintaining activities such as employment, nutrition, and social engagement. These aspects are not considered part of PHC, to the detriment of those accessing it, as we can see in the above examples. Reform needs the leadership to drive these changes.

PHC and UHC become most effective when prevention and other public health measures can lead to more equity for patients. Political economy analysis says it involves economic and political decisions that are often made favouring health/disease industry interests promoting further inequity. For patients UHC has as a fundamental base goal of equality, and this is foremost a political consideration. Groups such as indigenous, refugee, migrant, the poor and disabled have somewhat limited access to resources and to influence decision makers. For diabetes and multiple sclerosis as well as other conditions there are large costs for the economy and community in terms of productivity, healthcare and wellbeing. People with these conditions in many cases face diminished lifestyles and have less equality in terms of UHC.

The experience of the early stages of COVID-19 has shown that inequity is endemic to many social, political and health systems and that it needs to be addressed in future planning not only to provide effective healthcare but to sustain employment and the provision of effective social and economic supports.

\section{References}

1.Sturmberg JP, Martin CM. Universal health care - A matter of design and agency? J Eval Clin Pract 2020 doi/epdf/10.1111/jep.13395.

2. Kurowski C, Evans DB, Irwin A, Postolovska I. COVID - 19 (coronavirus) and the future of health financing: From resilience to sustainability. World Bank Blog May 2020 [Available from https://blogs.worldbank.org/health/covid-19-coronavirus-and-future-health-financing-resiliencesustainability accessed June 3 2020].

3. WHO UHC Health Financing 2019? [Available from: https://www.who.int/news-room/factsheets/detail/universal-health-coverage-(uhc) accessed May-7 2020]

4. Sparkes SP, Bump JB, Ozcelik EA, Kutzin J, Reich MR. Political economy analysis for health financing reform Health Syst and Reform 2019;5;(3);183-194. 
5. Reich MR. Political economy analysis of health. Bull World Health Organ 2019;97;514

6. Reich MR Political economy of non-communicable diseases: From unconventional to essential Health syst and reform 2019;5;(3);250-256.

doi: $10.1080 / 23288604.2019 .1609872$

7. Bambra C, Fox D, Samuel AS. Towards a politics of health, Health Promot Int 2005;20(2);187-193.

8. Boxall A-M, Short SD. Political economy and population health. Is Australia exceptional? Aust New Zealand Health Policy 2006;3:6. doi:10.1186/1743-8462-3-6

9. Gilfillan G. Inequity and disadvantage Parliamentary Library, Canberra, 2018 [Available from: https://www.aph.gov.au/About_Parliament/Parliamentary_Departments/Parliamentary_Library/pubs/BriefingBook46p/Inequality accessed May-162020].

10. Schofield D, Cunich MM, Shrestha RN, et al., The economic impact of diabetes through lost labour force participation on individuals: evidence from a microsimulation model. BMC Public Health 2014;4;14;220; doi: $10.1186 / 1471-2458-14-220$..

11. Schofield D, Shrestha RN, Cunich MM, et al., The costs of diabetes among Australians aged 45-64 years from 2015 to 2030: projections of lost productive life years (PLYs), lost personal income, lost taxation revenue, extra welfare payments and lost gross domestic product from Health\&WealthMOD2030 BMJ Open. 2017;7(1); e013158

12. Sainsbury E., Shi Y, Flack J, Colagiori S. Burden of diabetes in Australia: It's time for Action, University of Sydney, Australia 2018 [Available from https://www.sydney.edu.au/content/dam/corporate/documents/faculty-of-medicine-and-

health/research/centres-institutes-groups/burden-of-diabetes-its-time-for-more-action-report.pdf accessed May-10 2020]

13. Ahmad H, Palmer AJ, Campbell AJ, van der Mer I, Taylor B. Health economic impact of Multiple Sclerosis in Australia, 2017, Menzies Institute for Medical Research, University of Tasmania. 2018. [Available from: https://msra.org.au/wp-content/uploads/2018/08/health-economic-impact-of-ms-in-australia-in2017_ms-research-australia_web.pdf accessed May-30 2020].

14. Chen J, Taylor B, Palmer AJ. et al., Estimating MS-related work productivity loss and factors associated with work productivity loss in a representative Australian sample of people with multiple sclerosis Mult Scler J 2019. https://doi/10.1177/1352458518781971

15. Chen J, Taylor B, Winzenberg T, et al., Comorbidities are prevalent and detrimental for employment outcomes in people of working age with multiple sclerosis Mult Scler J 2019. https://doi/10.1177/1352458519872644

16. Chiriboga D, Garay J, Buss P, Madrigal RS, Rispel LC. Health inequity during the COVID - 19 pandemic: A cry for ethical global leadership. The Lancet 2020;395;10238;1690-1691.

17. Coates B, Cowgill M, Mackey W, Chen T. The employment impact of COVID - 19? It's bad. The Grattan Institute $19^{\text {th }}$ April 2020 [Available from: https://grattan.edu.au/news/the-employment-impact-ofcovid-19-its-bad/ accessed June-5 2020].

18. Harris J, Smithers K, Spina N. More than $70 \%$ of academics at some universities are casual. They're losing work and are cut out of JobKeeper.The Conversation 2020 [Available from: https://theconversation.com/more-than-70-of-academics-at-some-universities-are-casuals-theyrelosing-work-and-are-cut-out-of-jobkeeper-137778 accessed June-6 2020].

19. Hayne J. Coronavirus sent shockwaves through the Australian job market. Here are the numbers you need to know ABC News $14^{\text {th }}$ May 2020 [Available from: https://www.abc.net.au/news/2020-05-14/coronavirusjob-figures-numbers-released/12248280 accessed June-6 2020]. 
20. Department of Health Australia. Coronavirus (COVID - 19) advice for older people 2020. [Available from: https://www.health.gov.au/news/health-alerts/novel-coronavirus-2019-ncov-health-alert/advice-forpeople-at-risk-of-coronavirus-covid-19/coronavirus-covid-19-advice-for-older-people accessed June-6 2020].

21. Chin NC. COVID - 19 measures leave Southeast Asia's migrant workers exposed, lay bare their living conditions. Eco - Business 2020 [Available from https://www.eco-business.com/news/covid-19-measuresleave-southeast-asias-migrant-workers-exposed-lay-bare-their-living-conditions/ accessed June-6 2020].

22. Bibby J, Everest G, Abbs I. Will COVID-19 be a watershed moment for health inequalities? The Health Foundation 2020 [Available from: https://www.health.org.uk/publications/long-reads/will-covid-19be-a-watershed-moment-for-health-inequalities accessed May-9 2020]

23. Rothstein J. The Lost Generation? Scarring after the Great Recession 2019.[Available from https://eml.berkeley.edu/ jrothst/workingpapers/scarring.20190128.pdf accessed April-19 2020].

24. Robertson A. Superannuation early withdrawal risks collapsing the retirement system. ABC News $28^{\text {th }}$ April 2020 [Available from: https://www.abc.net.au/news/2020-04-28/superannuation-early-withdrawalrisks-retirement-system-collapse/12192580 accessed June-8 2020].

25. Eichengreen B. The human capital costs of the crisis. Project Syndicate 2020 [Available from: https://www.project-syndicate.org/commentary/covid19-pandemic-erosion-of-human-capital-by-barryeichengreen-2020-4?tm_source=Project+Syndicate+Newsletter\&utm_campaign=601e347d94-covid_newsletter_16_04_2020\&utm_medium=email\&utm_term=0_73bad5b7d8-601e347d94-107040033\&mc_cid=601e347d94\&mc_eid=2c5a4621d7 accessed April-20 2020].

26. Jackson H, Shiell A. Preventative health: How much does Australia spend and is it enough Department of Public Health La Trobe University, Australian Prevention Partnership Centre 2017 [Available from: http://fare.org.au/wp-content/uploads/Preventive-health-How-much-does-Australia-spend-andis-it-enough_FINAL.pdf accessed June-7 2020].

27. Webster I. The UK COVID - 19: Lessons for the UK and some for Australia. John Menadue: Pearls and irritations $4^{\text {th }}$ June 2020 [Available at: https://johnmenadue.com/uk-and-covid-19-lessons/?mc_cid=4ae3cbcefc\&mc_eid=288b620ff0 accessed June-6 2020].

28. Starfield B, Shi L, Macinko J. Contribution of primary health care to health systems and health. Milbank Q 2005;83;3;457-502.

29. McDonald J, Jayasuriva R, Harris MF. The influence of power dynamics and trust on multidisciplinary collaboration: A qualitative case study of type 2 diabetes mellitus BMC Health Serv Res 2012;10.1186/14726963-12-63.

30. Woodruff T, COVID -19 and lessons for our health system Croakey 22 ${ }^{\text {nd }}$ April 2020 [Available from: https://croakey.org/covid-19-and-lessons-for-our-health-system/ accessed June-6 2020]..

31. Thorpe M, Sweeny S. Call for the establishment of a primary health care minimum data set Deeble Institute Issues Brief no 29. Australian Healthcare and Hospital Association, 2019.

32. Consumer Health Forum of Australia. Out of pocket pain Deakin, ACT, Australia April 2018 [Available at: https://chf.org.au/sites/default/files/20180404_oop_report.pdf accessed June-7 2020].

33 .Peterson CL, Walker C. Are Medicare and Pharmaceutical Benefit Scheme services too costly for patients? An Epilepsy based study Aust J Soc Issues 2018;53;4: 386-399.

34. AIHW Australia's health: In brief. Australian Institute of Health and Welfare 2018 [Available from: https://www.aihw.gov.au/reports/australias-health/australias-health-2018-in-brief/contents/how-dowe-use-health-care accessed June-10 2020].

35. Shiell A, Jackson H. How much does Australia spend on prevention and how would we know whether it is enough? Health Promot J Austr 2018; https://doi.org/10.1002/hpja.165 


\section{Acknowledgments}

We wish to acknowledge A/Prof Joachim Sturmberg and A/Prof Carmel Martin for the opportunity to comment on their work on UHC and PHC.

\section{Conflict of Interest}

Neither of the authors have any conflicts of interest. 